\title{
Bliska suradnja krčkoga biskupa Antuna Mahnića i trećoredaca
}

\begin{abstract}
Dolazak biskupa Antuna Mahnića (Kobdilja na goričkom Krasu, Slovenija, 14. IX. 1850. - Zagreb, 14. XII. 1920.) na Krk u ono je vrijeme bio znakovit jer se u očima javnosti ponajprije promatrao u vidu daljnjega opstanka staroslavenskoga bogoslužja u Krčkoj biskupiji. Mahniću, čovjeku jasnih stavova i pronicljiva duha, bilo je razumljivo da, ukoliko se želi suživjeti s biskupijom u koju je poslan, odmah treba pretresti zatečenu liturgiju i glagoljicu. Stoga je sasvim logično da je u franjevcima trećorecima glagoljašima pronašao bliske suradnike. Dragutin Antun Parčić (Vrbnik na Krku, 26. V. 1832. - Rim, 25. XII. 1902.), vrstan poznavatelj glagoljice i izdavač glagoljskoga misala te donedavni trećoredac, stvorio je preduvjete za osnivanje Staroslavenske akademije na Krku. Suradnja krčkoga biskupa s trećorecima nastavila se te se još više produbila. Sretna je okolnost ta što je u ono doba u Krku bilo nekoliko fratara vještih s perom i oduševljenih Mahnićevim vizijama stvaranja Hrvatskoga katoličkog pokreta, koji je crkvenim i društvenim gibanjima te organizacijama obilježio prvu polovinu 20. stoljeća. Oni su se uključili u biskupove izdavačke pothvate. O. Ignacij(e) Radić (Sv. Vid-Miholjice kod Malinske, 28. VIII. 1876. - Porat kod Malinske, 30. VII. 1965.), pisac brojnih članaka u časopisu Hrvatska straža, postao je jedan od najbližih Mahnićevih suradnika. Prelaskom trećoredaca na kopno nastavila se suradnja. I nakon Mahnićeve smrti o. Ignacije piše o njemu, a u povodu 20. obljetnice smrti objavljuje njegov životopis (Doktor Antun Mahnić, biskup krčki, 1940.). Ne začuđuje činjenica da je mrtvo tijelo biskupa Mahnića, najprije položeno u kanoničku grobnicu na Mirogoju, nakon devet godina s Mirogoja preneseno na Ksaver te je u trećoredskoj crkvi sv. Franje Ksaverskoga ostalo sve do 2002.
\end{abstract}

\section{Uvod}

Nakon premještaja biskupa Andrije Šterka iz Krka u Trst, car Franjo Josip imenovao je 22. studenog 1896. profesora u goričkoj bogosloviji, dr. Antuna Mahnića (Kobdilja na goričkom Krasu, Slovenija, 14. IX. 1850. - Zagreb, 14. XII. 1920.), krčkim biskupom. Papa Lav XIII. potvrdio je imenovanje 3. prosinca. U slovenskoj javnosti Mahnić (Mahnič) nije bio toliko uočljiv kao profesor Novoga zavjeta, već kao javni radnik, pisac brojnih teoloških i literarnih rasprava, nerijetko polemičar u tonu, pokretač, pisac i vlasnik revije Rimski katolik, inicijator slovenskog katoličkog skupa u Ljubljani 1892., otkada se može reći da u Sloveniji datira novo katoličko gibanje, utemeljitelj izdavačke 
kuće Leonova družba, čovjek jasnih ideja i izrazito rimske orijentacije. Njegov prelazak iz Gorice u Krk djelovao je zbunjujuće, neočekivano i znakovito. Mnogi su se pitali: što se želi postići Mahnićevim preuzimanjem krčke biskupske stolice? Sam čin imenovanja probudio je mnoge slutnje i nagađanja, vjerojatno ne bez razloga.

\section{Razlozi uznemirenosti najavom imena novoga biskupa}

Budući da se na krčko-istarskom kraju u to doba rasplamsala žustra borba oko očuvanja glagoljice, a kapitularni vikar u Krku dr. Franjo Volarić - najviše spominjan kao „episcopabilis“ - ispunjavao je novinske stupce, ponajviše u listu Naša sloga, s argumentima obrane postojećeg staroslavenskog bogoslužja nasuprot mons. Giuseppeu Pesanteu iz Poreča i drugim osporavateljima ${ }^{1}$, javnost zainteresirana za glagoljsku baštinu s pravom je bila uznemirena o stavu koji će zauzeti novi biskup prema još nepoznatom „bogoslužnom privilegiju“ $u$ Krčkoj biskupiji. Naime, u to se vrijeme u očima inteligencije sačuvan slavenski jezik u liturgiji vrednovao s nacionalnog gledišta. Ponekad čak, izvan crkvenog konteksta, kao simbol borbe za nacionalna prava. ${ }^{2}$ Stoga je naglašena rimska orijentacija goričkog profesora, a sada imenovanog krčkog biskupa, mnogima ulijevala strah, a drugima nadu da će energični i još mladi Mahnić bez većih problema dokrajčiti opstanak slavenskog bogoslužja i glagoljice. Ubrzo se pročulo kako je Mahnić, pišući u Rimskom katoliku o slovenskim zbivanjima, zauzeo sasvim negativan stav u slučaju „Ricmanje“ ${ }^{\text {“3 }}$ kad su župljani, predvođeni svojim kapelanom, htjeli uvesti staroslavenski liturgijski jezik, a da za to nisu postojali valjani razlozi. Očitu bojazan o pretpostavljenom stavu novoga biskupa prema glagoljici nije skrivao ni narodni zastupnik, sada već časni starina, dr. Dinko Vitezić ${ }^{4}$, kao ni mnogi tadašnji listovi i novine koji su komentirali Mahnićevo imenovanje. ${ }^{5}$

1 Listovi u kojima se vodila polemika oko obrane i negiranja staroslavenskog bogoslužja bili su: Naša sloga (Trst), L'eko del Litorale (Gorica), L'Istria (Poreč).

2 Već revolucionarne 1848. na velikoj narodnoj skupštini u Zagrebu iznesen je zahtjev za uvođenjem staroslavenskog jezika u liturgiju kod svih Hrvata (HORVAT 1960: 254-255).

3 Kad su vjernici manjeg sela u okolici Trsta bez posebnog opravdanja htjeli uvesti staroslavenski jezik u liturgiju.

4 U pismu - božićnoj čestitki đakovačkom biskupu Strossmayeru napisao je sljedeće: „Od njegove, tj. Mahnićeve prošlosti ne možemo se nadati nikakvom probitku za narodnu stvar, navlastito u pogledu njegovih nazora o glagoljici“ (STRČIĆ 1969: 231).

5 BOZANIĆ 1991: 36. 


\section{Govor gesta jači od samih riječi}

Za današnjeg papu Franju kaže se da je on osoba prepoznatljiva po gestama, a njegov je prethodnik Benedikt XVI. čovjek dubokih misli i ideja. Izgleda da je ondašnji krčki kler shvatio ono što danas nazivamo public relation i razumio govor gesta. Prigodom biskupskog ređenja u Gorici, 7. veljače 1897., delegacija krčkog klera na poklon svom novom pastiru donijela je lijepo uvezani, prije nepune četiri godine izdan Parčićev glagoljski misal. Gesta nije predstavljala improvizaciju, već osmišljenu znakovitost, prenoseći snažnu poruku. Mahnić ju je - kako pokazuje daljnji slijed događaja - vrlo dobro shvatio. Dana 25. ožujka 1897. novozaređeni biskup stigao je u Krk, u mjesto svoga rezidiranja. Na obali ispred same biskupijske palače dočekali su ga krčki vjernici. Talijanska manjina došla je u pratnji puhačkog orkestra. Kler je predvodio već spomenuti mons. Franjo Volarić, Mahnićev poznanik s bečkog sveučilišta. Uz dobrodošlicu, novi je biskup iz usta kapitularnog vikara čuo i ovo upozorenje: „Znamo za upute koje imate glede glagoljice, ali se ti planovi mogu ostvariti samo preko naših tjelesa“" 6 Kako vidimo, riječi su bile jasne i jetke te nimalo sladunjave.

Preuzevši biskupijsku službu u Krku 1897., Antun Mahnić zatekao je staroslavensko bogoslužje u većini župnih crkava i kapela, osim u krčkoj katedrali, rapskoj nadžupnoj crkvi, osorskoj i creskoj zbornoj crkvi te župnoj crkvi u Malom i Velom Lošinju. U obavljanju staroslavenske službe Božje narod je živo sudjelovao. Sve je davalo naslutiti kako će prva briga novom pastiru - ukoliko se želi suživjeti s Biskupijom u koju je došao - biti odnos prema staroslavenskom liturgijskom jeziku. Međutim, nije bilo jasno kakav će stav zauzeti o tome.

\section{Afirmacija staroslavenske liturgije i glagoljske kulture}

Mahnić je odmah prionuo na posao. Kad je koncem 1898. tršćanski namjesnik T. Rinaldini, prema nalogu Vlade, došao na Krk i postavio pitanje biskupu o stavu prema glagoljici, Mahnić mu je odgovorio: „Još nisam dospio, ekscelencijo, da pitanje glagoljice proučim. Ali vam već sada otvoreno kažem da pitanje glagoljice temeljito proučavam, te ako pronađem da ono zakonito postoji, ne samo da je neću ukinuti, nego ću je svom dušom braniti““?

Za generalnog vikara novi je biskup uzeo upravo mons. Volarića, dobrog poznavatelja glagoljske baštine, koji mu je, bez sumnje, mnogo pomogao u razumijevanju prilično zamršene problematike. Kao i mnoge stvari, Mahnić je pitanje

Ove riječi navodi A. Toljanić, najvjerojatnije na temelju prepričavanja starijih (TOLJANIĆ 1970: 7).

7 MATULIĆ I JURETIĆ 1921: 252. 
glagoljice razmotrio vrlo ozbiljno. Sâm je istraživao povijesne izvore i crkvene dokumente. Župniku Bercetu, kod koga je svake godine provodio praznike, jednom je zgodom priznao: „Jako sam mnogo morao studirati. Nijedan ispit nije za mene bio tako težak kao ovo; sve sam morao sam tražiti, sve dukumente sam naći i proučiti““. ${ }^{8}$ Ujedno je postajao svjestan onoga što su i drugi zapažali: da glagoljsko bogoslužje propada zbog nedovoljnog poznavanja jezika te nedostatnih uvjeta $i$ pomagala za ovladavanje tim pismom. Kao čovjek od akcije, počeo je razmišljati kako da glagoljskom bogoslužju dade solidniju osnovu, stvori preduvjete, namakne sredstva i pronađe ljude za taj posao.

U krčkom svećeniku, kanoniku Dragutinu Parčiću (Vrbnik na Krku, 26. V. 1832. - Rim, 25. XII. 1902.), gledao je prvog suradnika, ali ga je, nažalost, smrt naglo pokosila. Ljeti 1898. Mahnić se u Krku susreo s mladim češkim svećenikom i slavistom Josipom (Josephom) Vajsom (Dolní Liboc, danas dio Praga, 17. X. 1865. - Prag, 2. VII. 1959.), u kojem je intuitivno prepoznao budućeg suradnika. Započelo je njihovo dopisivanje i međusobno uvažavanje na polju glagoljice. Poznato nam je kako su se stvari odvijale. Već je na Prvoj krčkoj sinodi 1901. biskup Mahnić ozakonio upotrebu glagoljice, a zatim osnovao Staroslavensku akademiju. Površnom promatraču moglo bi se učiniti da je biskup Antun Mahnić donošenjem mjerodavnih odluka o glagoljskom bogoslužju u Krčkoj biskupiji za svoje područje riješio samo jedan više-manje crkveno-pravni problem, doduše, u vrlo osjetljivom trenutku i na opće zadovoljstvo šire javnosti. Međutim, ako se taj problem bolje promotri, otkrit će se da biskupove, naoko pravne, odredbe u sebi nose određeno teološko, pastoralno i kulturno obilježje. $\mathrm{Na}$ temelju spoznaje da je crkvenoslavenski jezik u legalnoj upotrebi, glagoljsko bogoslužje, njegovano i zatečeno na području Biskupije, odjednom je dobilo novu vrijednost, a cjelokupna glagoljska kultura, utemeljena na tisućljetnoj liturgijskoj upotrebi staroslavenskog jezika, poprimila je novo značenje.

\section{Putem glagoljice otvoren put prema glagoljašima}

Nema sumnje da je upravo zauzimanjem odgovarajućeg stava prema staroslavenskom bogoslužju i glagoljici na području Krčke biskupije biskup Antun Mahnić uspostavio solidne temelje odnosa i suradnje s trećorecima, koji već u svojem naslovu nose oznaku glagoljaša. Utoliko više što se u samom gradu Krku, gotovo nadomak biskupijske zgrade, nalazio trećoredski samostan, a još su dva bila na samom otoku: jedan na Glavotoku, a drugi na Portu. Valja računati i na činjenicu da je u samom gradu Krku liturgija bila na latinskom jeziku, dok je po svim ostalim otočkim mjestima bila na staroslavenskom, a u Krku se glagoljalo samo kod trećoredaca. Iako su samostani na Glavotoku i na Portu imali dužu tradiciju,

SREBRNIČ 1921: 250. 
Mahnić će se jače povezati sa samostanom u Krku, odnosno s fratrima koji su u njemu živjeli i djelovali, zbog same činjenice da se nalazio u biskupijskom središtu.

Iako nemamo naznaka da su trećoreci direktno pomogli Mahniću u pronalaženju puta ozakonjenja staroslavenskog bogoslužja, indirektno je rad bivšeg trećoreca Dragutina Parčića biskupu bio od velike pomoći, a na njega je ujedno računao kao na prvog suradnika u radu ustanove za promicanje Staroslavenske akademije. ${ }^{9}$ Međutim, Parčića je, kako je već spomenuto, pretekla smrt neposredno prije otvorenja same ustanove. Što se same glagoljice i rada ondašnje Staroslavenske akademije tiče, može se čak primijetiti da stručne osobe u to doba nisu dolazile iz redova trećoredaca. Ipak je Mahnić pronašao bliske suradnike u mlađem naraštaju trećoredaca, koji će posebice surađivati u njegovim izdavačkim programima, a pogotovo u djelovanju Hrvatskog katoličkog pokreta.

\section{Stanje kod trećoredaca}

Tijekom pripreme ovog priopćenja o bliskoj suradnji biskupa Mahnića i trećoredaca pronašao sam kako je na simpoziju o Mahniću - koji je Slovenska teološka akademija organizirala 1989. u Rimu - o. fra Anđelko Badurina govorio o sličnoj temi, pa ću se poslužiti nekim podacima koje je on prikupio. ${ }^{10}$

Tijekom 19. stoljeća opće stanje u Provinciji franjevaca trećoredaca bilo je prilično sumorno. Broj je redovnika drastično opao, a život se u pojedinim samostanima pretvorio u svojevrsno životarenje. Čak se razmišljalo o zatvaranju ili prenamjeni nekih samostana, među kojima se nalazio i onaj u Krku. Međutim, u međuvremenu su na čelo provincije došla dvojica značajnih provincijala, obojica iz Dubašnice: o. Josip Turčić (1814. - 1877.) i o. Josip Dujmović (1833. - 1884.). Posebno se istaknuo o. Dujmović, koji je svojim stavovima i programima uveo novi duh, stavio naglasak na odgoj mladih ljudi, tako da se u kratko vrijeme, otprilike do kraja istoga stoljeća, zajednica trećoredaca obnovila i brojčano ojačala. Više je mlađih fratara stjecalo znanje izvan domovine i osposobilo se za razne aktivnosti. Stoga je Mahnić, preuzimanjem biskupske službe u Krku, kod trećoredaca zatekao prilično povoljno stanje, što znači da je kod njih - mlađih fratara - mogao pronaći vrijedne suradnike.

\section{Uspostavljena plodna i trajna suradnja}

Iz pisanih svjedočanstva samih trećoredaca jasno se isčitava da se njihov odnos prema krčkom biskupu Mahniću odvijao u znaku trajne suradnje, međusobnog razumijevanja i povjerenja. Ovakvo međusobno uvažavanje i suradnja postojala

\footnotetext{
BOZANIĆ I STRČIĆ 2002.

10 BADURINA 1990: 395-399.
} 
je cijelo vrijeme Mahnićeva biskupovanja, a produžilo se - kako ćemo vidjeti - i nakon biskupove smrti. Trećoredac Ignacij(e) Radić, kojega je biskup Mahnić zaredio za svećenika u Krku 1899., postao je biskupov odani suradnik, urednik, pisac brojnih članaka, njegov pratilac u zatočeništvo, višegodišnji ispovjednik; nije se udaljio od Mahnića ni u njegovim zadnjim danima života, a poslije je postao piscem njegova objavljenog životopisa (Doktor Antun Mahnić, biskup krčki, 1940.), kao i još jednog dosad neobjavljenog, ali, nažalost, negdje zagubljenog. $\mathrm{Na}$ njega me upozorio trećoredac o. Antun Badurina, sada gvardijan samostana $u$ Krku, a bit će veoma korisno ako se uspije pronaći. U Mahnićevu životopisu sâm Radić piše: „Napose je nas trećorece - a to znam iz vlastitog iskustva - biskup veoma rado imao". Ali o o. Ignaciju Radiću opširnije će progovoriti drugi izlagač. ${ }^{11}$ Osim o. Radića, bilo je još trećoredaca s kojima je Mahnić jače surađivao.

\section{Višestruka suradnja s trećorecima}

Biskup Mahnić uspostavio je višestruku suradnju s trećorecima. Budući da su mnogi od njih bili u suglasju s biskupom o Hrvatskom katoličkom pokretu i o radu sa svećenicima, bili su raspoloživi za suradnju, posebice u izdavačkim programima. Nabrojimo neke od njih:

a) o. Ignacij(e) Radić autor je više članaka u časopisu Hrvatska straža i u drugim listovima koje je pokrenuo biskup

b) o. Ljudevit Brusić, a poslije i o. Augustin Bajčić bili su odgovorni urednici lista Svećenička zajednica tijekom cijelog vremena njegova izlaženja (1911. - 1918.), a urednik je bio o. Igracije Radić, premda je urednički popis ostao u biskupovu nadležništvu

c) iz trećoredskog samostana u Krku širio se časopis Hrvatska straža, listovi SS. Eucharistia, Svećenička zajednica i druga izdanja tiskare „Kurykta“. Klerici su bili najviše zauzeti tim poslom.

Nadalje, trećoreci su se i pastoralno angažirali. Biskup im je povjerio službe kapelana u Krku, Poljicima, Dubašnici, Velom Lošinju i, po potrebi, u drugim župama. Klerici su posluživali u pontifikalnim obredima u katedrali. O. Ignacij(e) Radić u životopisu navodi kako se Mahnić posebno radovao otvaranju samostana u Zagrebu na Ksaveru, prvog u hrvatskoj unutrašnjosti. Biskup se veselio što će u njemu djelovati glagoljaši. Spominje i riječi kojima ih je hrabrio: „Pođite, pođite u Zagreb. Vi možete ondje s glagoljicom u svetim obredima donijeti velikih koristi Crkvi i narodu našemu“" ${ }^{12}$ Kao da je intuitivno znao da će i sâm jednog dana ondje naći počinak.

${ }_{11}$ Vidi rad Franje Emanuela Hoška Svjedočanstvo Ignacija Radića o Hrvatskom katoličkom pokretu.

12 RADIĆ 1940: 255. 


\section{Blizina u kritičnim trenucima i poslije biskupove smrti}

Već spomenuti bliski suradnik i prijatelj o. Ignacije Radić 4. travnja 1919. pratio je biskupa na talijanskom ratnom brodu, koji ga je odveo u zatočeništvo u Italiju, u Frascati blizu Rima. Dopratio ga je samo do Ancone, a zatim se, prema naređenju vojnih vlasti, morao vratiti. Bio je prisutan i u Zagrebu kad je Mahnić bio na umoru. Mrtvo tijelo krčkoga biskupa položeno je u kaptolsku grobnicu na Mirogoju, a nakon devet godina, tj. 3. studenog 1929., svečano su preneseni biskupovi posmrtni ostaci iz Mirogoja u crkvu trećoredaca na Ksaver, u novosagrađenu bočnu kapelicu Gospe Lurdske. Ondje je počivalo tijelo krčkoga biskupa sve do 23. studenog 2002., kad je - nakon izvršene ekshumacije - svečano preneseno u Krk i položeno u katedralu u kojoj je blagopokojni biskup obavljao svoju pastirsku službu. I tog su dana trećoreci na simboličan način dopratili biskupa, koji je s njima bio blizak, a njegovo su mrtvo tijelo u svojoj crkvi čuvali 73 godine, sve do vratiju krčke katedrale, nakon čega su ga prihvatili biskupijski svećenici i unijeli u biskupovu stolnu crkvu. Čini se da iz groba velikog biskupa Antuna Mahnića žare iskre svetosti. Pokrenut je proces njegove beatifikacije.

\section{Zaključak}

Iz navedenih se činjenica jasno razabire kako je između biskupa Antuna Mahnića i trećoredaca u Krku postojala bliska suradnja te obostrano povjerenje i uvažavanje, koje je potrajalo tijekom cijeloga biskupova života, a produženo je i nakon njegove smrti. Trećoreci su prepoznali duhovni lik i djelo svetoga biskupa te radosno prihvatili suradnju s njime. Krčki je biskup uzvratio povjerenjem. Međusobna suradnja urodila je plodom.

\section{Bibliografija}

BADURINA, Anđelko. 1990. Biskup Mahnić i Provincija franjevaca trećoredaca glagoljaša. U Mahničev simpozij v Rimu, ur. Edo Škulj, 395-399. Zagreb-Celje: Slovenska teološka akademija u Rimu, Mohorjeva družba u Celju, Mohorjeva družba u Gorici, Kršćanska sadašnjost u Zagrebu.

BOZANIĆ, Anton. 1991. Biskup Mahnić - pastir i javni djelatnik u Hrvata [Krčki zbornik 22 - Posebno izdanje 16; Analecta Croatica Christiana 26 - Biblioteke Centra za koncilska istraživanja, dokumentaciju i informacije „Kršćanska sadašnjost“]. Zagreb-Krk: Povijesno društvo otoka Krka, Kršćanska sadašnjost.

BOZANIĆ, Anton (ur.). 2006. Duhovni lik i značenje krčkoga biskupa Antuna Mahnića (1850-1920). Zbornik radova sa znanstvenoga skupa održanoga prigodom prijenosa Mahnićevih posmrtnih ostataka iz Zagreba u Krk 23. studenoga 2002. godine, Malinska, 22. studenoga 2002. Krk: Biskupija Krk. 
BOZANIĆ, Anton, Petar STRČIĆ. 2002. Mahnić i njegova Staroslavenska akademija (U povodu prijenosa posmrtnih ostataka krčkog biskupa dr. Antuna Mahnića iz Zagreba u Krk, 23. studenoga 2002. godine) [Mala knjižnica „Krčkog zbornika“, knj. 3]. Krk: Poglavarstvo Grada Krka, Povijesno društvo otoka Krka, Naklada Vitagraf.

HORVAT, Josip. 1960. Ljudevit Gaj [Biblioteka Portreti, knj. 22]. Beograd: Nolit.

HORVAT, Josip. 1975. Ljudevit Gaj: njegov život, njegovo doba [Monografije-Biografije, knj. 4]. Zagreb: Liber (prošireno postumno izdanje).

L'eko del Litorale (Gorica).

L'Istria (Poreč).

MATULIĆ, Mario, Augustin JURETIĆ. 1921. Veliki svećenik naroda svoga. Čas-znanstvena revija „Leonove družbe“ XV/3-4: 252-258.

Naša sloga (Trst).

RADIĆ, Ignacij. 1940. Doktor Antun Mahnić, biskup krčki. Slavonska Požega: Naklada „Dobra štampa“.

SREBRNIČ, Josip. 1921. O počitnicah pri župniku Iv. Brencetu. Čas - znanstvena revija „Leonove družbe“ XV/3-4: 248-252.

STRČIĆ, Petar. 1969. Dopisivanje Dinko Vitezić - Josip Strossmayer (1874-1904). Vjesnik historijskih arhiva u Rijeci i Pazinu XIV: 173-264.

TOLJANIĆ, Antun. 1970. Antun Mahnić - biskup krčki. O 50. godišnjici smrti biskupa Mahnića. Rijeka: Župni ured u Malom Lošinju.

\section{Close Cooperation between Antun Mahnić, Bishop of Krk, and the Tertiaries}

The arrival of bishop Antun Mahnic at the island was at that time symbolic and looked upon by the public primarily in the light of the issue of continued existence of the Old Slavonic worship. Mahnić, a man of firm beliefs and sharp intellect, understood clearly that, if he was to learn to live with his new bishopric, he had to look immediately into the matter of the traditional liturgy and Glagolitic practice as found on the island. Therefore it is quite understandable that he was able to find close assistants among the island's Glagolitic friars of the third order. Dragutin Parčić, an excellent scholar of the Glagolitic script and publisher of a Glagolitic missal, himself a former tertiary monk, created the preconditions for the founding of the Old Church Slavonic Academy on the island of Krk. The cooperation between the bishop of Krk and the Glagolitic tertiaries was continued and further enhanced. It was a fortunate circumstance that at the time there were several friars living on the island and skilled with pen and also very enthusiastic about the new bishop's visions about the creation of a Croatian Catholic Movement. They participated in the bishop's publishing projects. Friar Ignacij(e) 
Radić, author of numerous articles in the Hrvatska straža journal, became one of Mahnićs closest associates. After the moving of the tertiary friars to the mainland the cooperation continued. After the death of Mahnić Ignacij(e) continued to write about him and on his $20^{\text {th }}$ death anniversary he published a biography of the great bishop. Therefore it is not surprising that the bishop's dead body, first deposed in the canons' tomb on Mirogoj, was after nine years moved to the church of tertiary monks on the hill of Ksaver and remained there till 2002.

Keywords: Antun Mahnić (1850 - 1920), The Monastic III Order of Holy Father Francis, Old Church Slavonic Academy in Krk

Ključne riječi: Antun Mahnić (1850. - 1920.), samostanski III. red svetoga oca Franje, Staroslavenska akademija u Krku

Anton Bozanić Župa Uznesenja Blažene Djevice Marije HR-51513 Omišalj, Prikešte 19 anton.bozanic@ri.t-com.hr 


\section{FILOZOFSKI FAKULTET SVEUČILIŠTA U ZAGREBU \\ ZAVOD ZA HRVATSKU POVIJEST \\ INSTITUTE OF CROATIAN HISTORY \\ INSTITUT FÜR KROATISCHE GESCHICHTE}
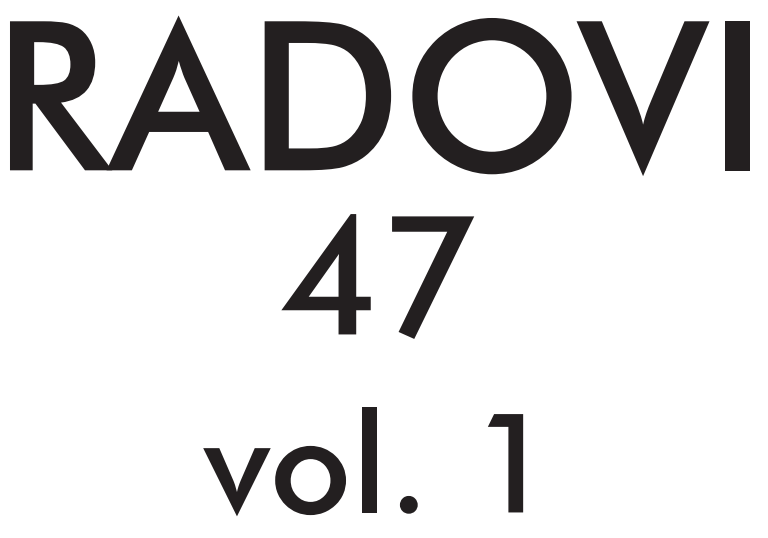

ZAVOD ZA HRVATSKU POVIJEST

FILOZOFSKOGA FAKULTETA SVEUČILIŠTA U ZAGREBU

\section{PF press \\ ZAGREB 2015.}




\title{
RADOVI ZAVODA ZA HRVATSKU POVIJEST FILOZOFSKOGA FAKULTETA SVEUČILIŠTA U ZAGREBU
}

\author{
Knjiga 47, vol. 1
}

\author{
Izdavač / Publisher \\ Zavod za hrvatsku povijest \\ Filozofskoga fakulteta Sveučilišta u Zagrebu \\ FF-press \\ Za izdavača / For Publisher \\ Vlatko Previšić \\ Glavni urednik / Editor-in-Chief \\ Hrvoje Gračanin \\ Izvršna urednica / Executive Editor \\ Inga Vilogorac Brčić \\ Uredništvo / Editorial Board
}

Bruna Kuntić-Makvić (stara povijest/ancient history), Zrinka Nikolić Jakus (srednji vijek/ medieval history), Hrvoje Petrić (rani novi vijek/early modern history), Željko Holjevac (moderna povijest/modern history), Tvrtko Jakovina (suvremena povijest/contemporary history),

Silvija Pisk (mikrohistorija i zavičajna povijest/microhistory and local history),

Zrinka Blažević (teorija i metodologija povijesti/theory and methodology of history)

Međunarodno uredničko vijeće / International Editorial Council

Denis Alimov (Sankt Peterburg), Živko Andrijašević (Nikšić), Csaba Békés (Budapest), Rajko Bratož (Ljubljana), Snježana Buzov (Columbus, Ohio), Svetlozar Eldarov (Sofija), Toni Filiposki (Skopje), Aleksandar Fotić (Beograd), Vladan Gavrilović (Novi Sad), Alojz Ivanišević (Wien),

Egidio Ivetić (Padova), Husnija Kamberović (Sarajevo), Karl Kaser (Graz),

Irina Ognyanova (Sofija), Géza Pálffy (Budapest), Ioan-Aurel Pop (Cluj),

Nade Proeva (Skopje), Alexios Savvides (Kalamata), Vlada Stanković (Beograd), Ludwig Steindorff (Kiel), Peter Štih (Ljubljana)

Izvršna urednica za tuzemnu i inozemnu razmjenu / Executive Editor for Publications Exchange Kristina Milković

Tajnik uredništva / Editorial Board Assistant

Dejan Zadro

Adresa uredništva/Editorial Board address

Zavod za hrvatsku povijest, Filozofski fakultet Zagreb, Ivana Lučića 3, HR-10 000, Zagreb

Tel. ++385 (0)1 6120 150, 6120 158, faks ++385 (0)1 6156879

Časopis izlazi jedanput godišnje / The Journal is published once a year

Časopis je u digitalnom obliku dostupan na / The Journal in digital form is accessible at Portal znanstvenih časopisa Republike Hrvatske „Hrčak“ http://hrcak.srce.hr/radovi-zhp

Financijska potpora za tisak časopisa / The Journal is published with the support by

Ministarstvo znanosti, obrazovanja i športa Republike Hrvatske

Časopis je indeksiran u sljedećim bazama / The Journal is indexed in the following databases:

Directory of Open Access Journals, EBSCO, SCOPUS, ERIH PLUS 
Naslovna stranica

Iva Mandić

Grafičko oblikovanje i računalni slog

Marko Maraković

Lektura

Samanta Paronić

Tisak

Web2tisak, Zagreb

Naklada

250 primjeraka

Časopis je u digitalnom obliku dostupan na Portalu znanstvenih časopisa Republike Hrvatske ,Hrčak“ http://hrcak.srce.hr/radovi-zhp

The Journal is accessible in digital form at the Hrcak - Portal of scientific journals of Croatia http://hrcak.srce.hr/radovi-zhp 


\section{RADOVI 47}

\section{vol. 1}

ZaVoda za hrVAtSku poviJest FILOZOFskoga fakulteta SVeuČILIŠTA u Zagrebu 


\title{
Tematski blok / Themed issue
}

\section{TREĆOREDSKA GLAGOLJAŠKA TRADICIJA U EUROPSKOM KONTEKSTU TERTIARY GLAGOLITIC TRADITION IN EUROPEAN CONTEXT}

\author{
Radovi međunarodnoga znanstvenog skupa \\ održanoga 27. i 28. IX. 2013. na Hrvatskom katoličkom sveučilištu u Zagrebu \\ u organizaciji \\ Provincije franjevaca trećoredaca glagoljaša u Zagrebu, Hrvatskoga katoličkog \\ sveučilišta u Zagrebu, Filozofskoga fakulteta Sveučilišta u Zagrebu - Odsjek za \\ povijest, Filozofskoga fakulteta Sveučilišta u Splitu - Odsjek za povijest, Instituta \\ za povijest umjetnosti u Zagrebu i Staroslavenskoga instituta u Zagrebu \\ Proceedings of the International Scientific Conference \\ held on 27th and 28th September 2013 at the Catholic University of Croatia in Zagreb \\ and organized by \\ the Province of the Glagolitic Friars of the Third Order Regular, Catholic University \\ of Croatia in Zagreb, Faculty of Humanities and Social Sciences of the University \\ of Zagreb - Department of History, Faculty of Humanities and Social Sciences of \\ the University of Split - Department of History, Institute of Art History, \\ and Old Church Slavonic Institute
}

Gosti urednici / Guest editors

\author{
Ivan BOTICA \\ Tomislav GALOVIĆ \\ Kristijan KUHAR
}

